\title{
Optimising pharmacotherapy for secondary prevention of non-invasively managed acute coronary syndrome
}

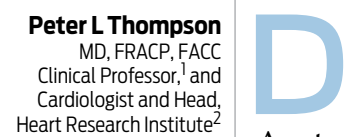

espite a trend towards greater use of coronary revascularisation, half of all patients who experienced an acute coronary syndrome (ACS) in Australia in 2012 had their conditions managed noninvasively - that is, they did not receive coronary angiography with subsequent coronary stenting or bypass surgery. ${ }^{1}$ The evidence base and international guidelines for the management of patients with ACS are extensive, ${ }^{2-4}$ but some research suggests that patients whose ACS is treated conservatively may not receive the same level of evidence-based care as those whose ACS is managed invasively. ${ }^{5}$

This article reviews the optimal pharmacological management of non-invasively managed ACS, and briefly reviews the evidence to support the prescription of each class of drug.

\section{Antithrombotic therapy}

As coronary thrombosis is the major cause of ACS, antithrombotic treatment regimens are now routine.

\section{Aspirin}

Aspirin in a dose of 75-325 $\mathrm{mg}$ daily is recommended in all guidelines for all patients after an ACS, regardless of whether revascularisation has occurred. ${ }^{2-4}$ Its low cost and high effectiveness make it an attractive agent to reduce the risk of recurrence of coronary thrombosis. In postACS patients, aspirin has been shown to reduce major vascular events by $25 \%$, with an absolute risk reduction of 35 vascular events per 1000 patients treated over 2 years. ${ }^{6}$ Prescribing levels well in excess of $95 \%$ for postACS patients have been reached in Australia. ${ }^{1}$

A limitation with aspirin therapy, even in low doses, is an increase in the risk of gastrointestinal side effects. A recent meta-analysis calculated that the odds ratio for the risk of major gastrointestinal bleeding in aspirin versus non-aspirin users was 1.55 (95\% CI, 1.27-1.90). ${ }^{7}$ Observational studies suggest that bleeding complications are fewer with lower doses of aspirin, ${ }^{8}$ but randomised allocation to low-dose (75-100 mg) versus standard-dose $(101-325 \mathrm{mg})$ aspirin in combination with clopidogrel showed no differences in bleeding at 30 days. ${ }^{9}$ Entericcoated versions of aspirin may have fewer adverse gastric effects than buffered aspirin, but it remains unclear whether it is the enteric coating or the lower dose that decreases the risk of gastric complications. ${ }^{10} \mathrm{Co}$-prescribing a proton pump inhibitor (PPI) reduces the risk of gastrointestinal bleeding, but the long-term cost-effectiveness of the combination with aspirin remains doubtful. ${ }^{11}$

\section{$\mathrm{P}_{2} \mathrm{Y}_{12}$ inhibitors and dual antiplatelet therapy}

Dual antiplatelet therapy (DAPT; aspirin and a P2Y 12 inhibitor drug) is now recommended for conservatively
Summary

About half of all patients who experience an acute coronary syndrome (ACS) in Australia have their conditions managed non-invasively - that is, they do not undergo coronary angiography and revascularisation in hospital.

ACS patients whose conditions are managed non-invasively may not receive the same level of evidence-based care as those who receive coronary revascularisation.

This article reviews the optimal pharmacological management of ACS managed non-invasively.

There is strong evidence to support the prescription of dual antiplatelet therapy (DAPT; aspirin with a $\mathrm{P}_{2} \mathrm{Y}_{12}$ inhibitor). DAPT should continue for 12 months after an ACS, then aspirin should be continued indefinitely.

Anticoagulation with warfarin or a novel oral anticoagulant may be needed if atrial fibrillation occurs; the combination with DAPT increases the risk of bleeding.

Unless contraindicated, high-intensity statin therapy should be prescribed for all post-ACS patients irrespective of their cholesterol level. Non-statin lipid therapy has not been shown to improve outcomes.

Use of $\beta$-adrenergic blockers is recommended in most guidelines, but the clinical trials to support this recommendation were performed more than 30 years ago, and routine long-term use may not be relevant to modern treatment, except when there is cardiac failure or left ventricular dysfunction.

Angiotensin-converting enzyme inhibitors or angiotensin receptor blockers are also widely recommended, but the evidence for benefit is stronger when there is left ventricular dysfunction.

Calcium-channel blockers, nitrates, antiarrhythmic drugs, digoxin and diuretics do not improve outcomes in post-ACS patients.

managed post-ACS patients in all guidelines. ${ }^{2-4}$ The CURE study, conducted nearly 15 years ago, showed a clear role for DAPT in conservatively managed ACS; patients treated with DAPT (clopidogrel and aspirin) had fewer subsequent coronary events than patients treated with aspirin alone. ${ }^{12}$ At 12 months, the CURE trial's end point of myocardial infarction or cardiovascular death was reduced by $20 \%$ (relative risk reduction, $0.80 ; 95 \% \mathrm{CI}$, 0.72-0.90; $P<0.001)$. This benefit came with a moderate increase in major bleeding (relative risk, $1.38 ; P=0.001$ ). All subsequent guidelines based on the CURE trial data recommend DAPT for conservatively managed ACS.

The ideal duration of DAPT after an ACS episode without percutaneous coronary intervention (PCI) remains unclear. While there are ongoing trials to examine the optimal duration of DAPT in patients treated with $\mathrm{PCI}_{1}^{13,14}$ the relevance of these trial results to conservative management is not clear. 


\begin{tabular}{lcc}
1 & \multicolumn{3}{l}{$\mathrm{P}_{2} \mathrm{Y}_{12}$ inhibitor antiplatelet drugs and dosages } \\
Drug & Loading dose & Maintenance dosage \\
\hline Clopidogrel & $300 \mathrm{mg}$ or $600 \mathrm{mg}$ & $75 \mathrm{mg}$ daily \\
Prasugrel & $60 \mathrm{mg}$ & $10 \mathrm{mg}$ daily \\
Ticagrelor & $180 \mathrm{mg}$ & $90 \mathrm{mg}$ twice daily
\end{tabular}

International guidelines recommend the combination of clopidogrel with aspirin for 12 months, as this was the treatment period examined in the CURE trial. ${ }^{2-4}$ Post-hoc review of the events curves in the CURE study showed that the major benefit of clopidogrel plus aspirin over aspirin alone was in the first 6 weeks after commencement of treatment, and there have been no comparative studies to evaluate shorter or longer periods of therapy. The benefits of longer-term DAPT over aspirin have not been confirmed. ${ }^{15}$

Concerns about resistance to clopidogrel in some patients have led to extensive research into clopidogrel resistance. "Clopidogrel resistance" is more correctly defined as high on-treatment platelet reactivity and, according to some estimates, up to $30 \%$ of patients are non-responders or poor responders to clopidogrel by this criterion. ${ }^{16,17}$ However, recent studies have shown that dosing based on platelet responsiveness to clopidogrel is unhelpful. ${ }^{18,19}$

Like aspirin, clopidogrel can increase the risk of gastrointestinal bleeding, and concomitant use of PPIs with clopidogrel has been closely examined, as several observational studies suggested that PPIs may interfere with the action of clopidogrel via competition for the cytochrome $\mathrm{P} 450$ pathway in the gut transport of the prodrug. ${ }^{20}$ However, a well conducted randomised trial of omeprazole showed no clinically significant interaction with clopidogrel, ${ }^{21}$ and the most recent meta-analyses have shown that an interaction between PPIs and clopidogrel is not significant for most patients. The earlier observations of adverse effects of the combination may have been due to PPI users being older patients, who are at increased risk of adverse cardiovascular events. ${ }^{22}$

Newer oral agents that inhibit the $\mathrm{P}_{2} \mathrm{Y}_{12}$ receptor (ticagrelor, prasugrel) have recently become available. Dosages for the three agents are summarised in Box 1.

Both ticagrelor and prasugrel are more effective in reducing subsequent coronary events, but carry a higher bleeding risk than clopidogrel. Most guidelines recommend that the newer agents are preferred for most ACS (both ST-elevation myocardial infarction and non-STelevation myocardial infarction) unless the risk of bleeding is excessive. ${ }^{2-4}$

Prasugrel was more effective than clopidogrel in the TRITON-TIMI 38 trial in reducing coronary events. ${ }^{23}$ However, this definitive trial of prasugrel only included patients for whom the coronary anatomy was known, and a coronary angiogram may not be available for patients whose ACS is managed conservatively. Prasugrel was ineffective for conservatively managed ACS. ${ }^{24}$ Because of bleeding risk, care is required in older patients $(>80$ years), and those who weigh under $60 \mathrm{~kg}$ or have renal impairment.
Ticagrelor was also shown to be more effective than clopidogrel at preventing stroke, myocardial infarction or death, as demonstrated in the PLATO trial. ${ }^{25}$ It also has an increase in overall bleeding risk, but as the trial evidence supporting its use did not require prior coronary angiography, it has the advantage as the preferred agent for initial treatment, particularly in the patient whose ACS is likely to be managed conservatively. ${ }^{26}$

\section{Warfarin and new oral anticoagulants}

Post-ACS vitamin K antagonists were evaluated in the 1990s and were shown to achieve a reduction in reinfarction, and are even more effective in reducing the risk of stroke but with an increased risk of bleeding. ${ }^{27}$ Based on this experience, two of the new oral anticoagulants (NOACs) have been tested in patients who had experienced a coronary event. Rivaroxaban was shown to reduce recurrences, but at an increased risk of bleeding. ${ }^{28}$ Apixaban did not reduce recurrent ischaemic events and caused increased bleeding. ${ }^{29}$

\section{Anticoagulants for atrial fibrillation after ACS}

Atrial fibrillation (AF) requiring an oral anticoagulant is a common comorbidity in patients with recent ACS being treated with DAPT. Patients with non-invasively managed ACS, AF and a zero $\mathrm{CHA}_{2} \mathrm{DS}_{2}$-VASc (congestive heart failure, hypertension, age $\geqslant 75$ years, diabetes mellitus, stroke, vascular disease, age 65 to 74 years, sex) score can be managed with aspirin or DAPT. ${ }^{30}$ However, patients with a moderate or high risk of stroke need to be considered for triple antithrombotic therapy (DAPT for their coronary disease and an anticoagulant for their AF), and this carries an increased risk of bleeding. Registry data have quantified this risk, showing that the combination of antiplatelet agents with warfarin increases the risk of bleeding by 1.50 for aspirin and by 1.84 for clopidogrel over warfarin alone. ${ }^{31}$

There are no trials to guide therapy for patients with non-invasively managed ACS and AF, but a randomised study of participants requiring anticoagulation and antiplatelet therapy after PCI demonstrated that double therapy with clopidogrel and warfarin was associated with significantly less bleeding than triple therapy with aspirin, clopidogrel and warfarin, without any increased risk of thrombotic events. ${ }^{32}$ To date, there are no data to guide the use of the NOACs with the newer P2 $\mathrm{Y}_{12}$ inhibitors, which are becoming standard care for patients after ACS.

\section{Lipid-modulating medications}

\section{Statins}

Statin therapy is an essential part of the post-ACS regimen. Meta-analyses of trials in patients who have had a coronary event have shown that subsequent coronary events can be reduced by $25 \%-30 \%,{ }^{33}$ with an absolute reduction of 48 major vascular events per 1000 treated for each $1 \mathrm{mmol} / \mathrm{L}$ reduction in low-density lipoprotein (LDL) cholesterol level. ${ }^{34}$ Commencement of the statin in hospital enhances adherence over subsequent months. ${ }^{35}$ Lower-potency statins are less effective, ${ }^{36}$ and a high-dose 
potent statin is more effective than a moderate-dose less potent statin, ${ }^{37}$ and equally safe. ${ }^{38}$ High-dose $(80 \mathrm{mg})$ simvastatin was associated with a higher than acceptable incidence of myopathy in a trial of post-ACS patients and should be avoided. ${ }^{39}$ While rosuvastatin has been shown to be effective in high-risk non-ACS cohorts, there is no specific trial to support its use after ACS. The target LDL cholesterol level for post-ACS patients is below $1.8 \mathrm{mmol} / \mathrm{L} .{ }^{40}$ It remains unclear whether a patient who achieves a reduction of LDL cholesterol to target levels with $80 \mathrm{mg}$ of atorvastatin should be prescribed a lowerdose statin to reduce side effects.

Many patients experience side effects while taking statins, but analysis of randomised trials has shown that major side effects are equally seen in participants treated with placebo and statins, apart from a small increase in type 2 diabetes. ${ }^{41}$ While myopathy is uncommon, symptoms of myalgia are common and quite often lead to early cessation of statin therapy.

\section{Non-statin lipid-modulating therapies}

Ezetimibe has the potential to lower LDL cholesterol levels, either alone or in conjunction with statins, ${ }^{42}$ but to date, there are no data to demonstrate any clinical benefit. The outcome of the IMPROVE-IT trial will be awaited with interest to see if lowering LDL cholesterol levels by non-statin therapy is effective. ${ }^{43}$

PCSK9 inhibitors have been shown to be highly effective in lowering LDL cholesterol levels among patients with hyperlipidaemia resistant to statins, and they have an acceptable safety profile, ${ }^{44,45}$ but the relevance of this to reducing risk among patients after ACS remains to be established.

\section{Triglyceride-lowering medications}

There is no clear-cut benefit for lowering triglyceride levels in patients after ACS. Trials of gemfibrozil ${ }^{46}$ and bezafibrate ${ }^{47}$ have not been sufficiently persuasive to establish fibrate therapy in post-ACS patients, and a large trial with fenofibrate did not achieve its primary end point in patients with high-risk type 2 diabetes. ${ }^{48}$

\section{High-density lipoprotein cholesterol-raising medications}

Trials of high-density lipoprotein (HDL) cholesterol-raising drugs have been disappointing. While cholesteryl ester transfer protein inhibitors can raise HDL cholesterol levels, they have not been shown to improve outcomes. A large torcetrapib trial in patients with stable coronary heart disease demonstrated an increased mortality. ${ }^{49} \mathrm{~A}$ large dalcetrapib study in patients with ACS showed an effective raising of HDL cholesterol levels, but no effect on outcomes. ${ }^{50}$ A preliminary study of anacetrapib showed that it could lower LDL cholesterol levels as well as raise HDL cholesterol levels, ${ }^{51}$ but a large outcomes study with anacetrapib is yet to be reported.

Alternative approaches to raising HDL cholesterol levels have been explored, so far without success. Niacin in patients with low HDL cholesterol levels receiving intensive statin therapy raised HDL cholesterol levels, but showed no additional benefit over statin therapy. ${ }^{52}$ Niacin combined with the anti-flushing agent laropiprant caused an unacceptable increase in risk of myopathy in patients taking simvastatin. ${ }^{53}$ The challenge in HDL cholesterol management may be to target the functionality of the HDL cholesterol, rather than simply the level. ${ }^{54}$

\section{Other therapies}

\section{Omega 3 fatty acids}

Fish oil-derived omega 3 fatty acids have been shown to moderately reduce total and sudden post-ACS deaths, but it is not clear if this is by a triglyceride-lowering effect or other mechanisms. ${ }^{55}$

\section{$\beta$-Adrenergic blockers}

$\beta$-Blockers are recommended for long-term post-ACS management in most guidelines. ${ }^{2-4}$ This is sound advice for most patients in the early post-ACS period, but the recommendation for long-term use of $\beta$-blockers is based on evidence obtained from clinical trials conducted in the 1980s. ${ }^{56}$ At that time, the definition of ACS was based on criteria quite different from the modern definition, which is based on subtle changes in troponin. ${ }^{57}$ In the 1980s, the definition of a myocardial infarction for a patient to be included in a post-myocardial infarction trial required major electrocardiogram changes and a doubling of cardiac enzymes. ${ }^{58}$ When the post-infarction oral $\beta$-blocker trials were conducted, ${ }^{59-61}$ many modern treatments, such as early intervention with PCI, the nearuniversal use of statin therapy and the widespread use of DAPT, had not been introduced to cardiology. The relevance of 30-year-old evidence derived from patients with extensive myocardial infarction to the treatment of patients in the modern era is doubtful. ${ }^{62}$

Recent evidence has shown no benefit of $\beta$-blockers on mortality in patients with hypertension ${ }^{63}$ or stable coronary heart disease, ${ }^{64}$ casting further doubt on the assumption that routine, long-term use of $\beta$-blockers in stable post-ACS patients is essential. In contrast, research among patients with left ventricular (LV) dysfunction or cardiac failure after myocardial infarction shows clear evidence of benefit for $\beta$-blockers. ${ }^{65,66}$

\section{ACE inhibitors and angiotensin receptor blockers}

Angiotensin-converting enzyme (ACE) inhibitors have a role in patients with cardiac failure and significant LV dysfunction. ${ }^{67}$ The use of ACE inhibitors in the absence of post-coronary LV dysfunction has been extensively studied, and meta-analysis of clinical trials in this group of patients shows a statistically significant but modest benefit, with 10 lives saved for 1000 patients treated over 4.4 years. ${ }^{68}$ A recent large observational registry study did not replicate the benefits of ACE inhibitors seen in clinical trials, and failed to demonstrate any improvement in survival among patients treated with ACE inhibitors. ${ }^{69}$ Angiotensin receptor blockade as an alternative to ACE inhibition has been trialled in post-ACS patients, but the evidence base for angiotensin receptor blockers (ARBs) is not as extensive as it is for post-infarction ACE inhibitors. ${ }^{70}$

\section{Aldosterone blockade}

Spironolactone and eplerenone have shown benefit in patients with cardiac failure and LV dysfunction. ${ }^{71,72}$ 
Eplerenone is approved for authority use on the Australian Pharmaceutical Benefits Scheme for patients with heart failure with an LV ejection fraction of $40 \%$ or less occurring within 3 to 14 days after an acute myocardial infarction. If spironolactone or eplerenone are prescribed for the post-ACS patient, meticulous monitoring of potassium levels is required, particularly for patients taking concomitant ACE inhibitors. ${ }^{73}$

\section{Calcium-channel blockers}

Calcium-channel blockers have not been shown to benefit prognosis for the post-infarction patient, and are not recommended as part of routine management. Verapamil and diltiazem are contraindicated in post-infarction patients with LV dysfunction. ${ }^{74,75}$ Amlodipine has been shown to be safe in the presence of LV dysfunction. ${ }^{76}$

\section{Antiarrhythmic drugs}

Antiarrhythmic drugs are not recommended, as they have not been shown to improve prognosis for patients who have had a myocardial infarction. ${ }^{77}$

\section{Nitrate therapy}

Nitrates are indicated for patients with symptomatic angina, but do not have a role for patients without angina after myocardial infarction. ${ }^{78}$

\section{Diuretics and digoxin}

Diuretics are useful for symptomatic relief of cardiac failure but have not been convincingly shown to improve prognosis for patients after ACS. ${ }^{79}$ The need for ongoing diuretic therapy should be reviewed at the time of hospital discharge, as unnecessary diuretic therapy can cause hypovolaemia and electrolyte disturbances.

Digoxin does not have a clear role except as an alternative to $\beta$-blockers for rate control of AF. ${ }^{80}$

\section{Conclusions}

Recommendations for optimal pharmacotherapy in the post-ACS patient are summarised in Box 2. Most patients will recover without symptoms or LV dysfunction. Patients in this category should be routinely prescribed DAPT and a high intensity statin. The DAPT should be continued for 12 months and the aspirin and statin indefinitely. All patients should be taking a $\beta$-blocker when they leave hospital, but the evidence for long-term continuation in the modern era is minimal, and further trials are needed to clarify the ideal duration of $\beta$-blocker therapy. While ACE inhibitors or ARBs are recommended in some guidelines, the evidence for their routine use in the patient free of cardiac failure or LV dysfunction is questionable.

Patients who have documented LV dysfunction after their ACS should have the same treatment as above, but in these patients the evidence for $\beta$-blockers and ACE inhibitors or ARBs is strong and they should be prescribed. The preferred $\beta$-blocker should be one of the agents shown to be effective in clinical trials of cardiac failure or LV dysfunction. There is good evidence that aldosterone antagonists are effective in patients with LV dysfunction.

Symptomatic patients with angina or dyspnoea or cardiac failure should be treated as above and have
2 Recommended treatment for patients whose acute coronary syndrome has been conservatively managed

Clinical scenario

Drug
Asymptomatic ventricular (LV)

dysfunction

dysfunction

\section{Symptomatic}

patient patient without left

Asymptomatic
Aspirin 100-150 mg per day indefinitely

$\mathrm{P}_{2} \mathrm{Y}_{12}$ inhibitor for 12 months

High-dose statin indefinitely

$\beta$-Blocker (long-term duration uncertain)

Consider angiotensin-converting enzyme (ACE) inhibitor or angiotensin receptor blocker

\section{As above}

Substitute a $\beta$-blocker shown to be effective in LV dysfunction (bisoprolol, carvedilol, nebivolol)

Add ACE inhibitor or angiotensin receptor blocker

Consider aldosterone antagonist (spironolactone or eplerenone)

\section{As above}

For angina symptoms, prescribe standard anti-anginal therapy, consider referral for angiography or revascularisation

Prescribe a diuretic for dyspnoea appropriate treatment for their angina or symptoms of cardiac failure.

Competing interests: Peter Thompson has received research funding from AstraZeneca, Boehringer Ingelheim, Pfizer, Bristol-Myers Squibb and Amgen and advisory board fees from AstraZeneca and Pfizer.

Provenance: Commissioned; externally peer reviewed.

1 Chew DP, French J, Briffa TG, et al. Acute coronary syndrome care across Australia and New Zealand: the SNAPSHOT ACS study. Med J Aust 2013; 199 : 185-191.

2 Hamm CW, Bassand JP, Agewall S, et al. ESC Guidelines for the management of acute coronary syndromes in patients presenting without persistent ST-segment elevation: the Task Force for the management of acute coronary syndromes (ACS) in patients presenting without persistent ST-segment elevation of the European Society of Cardiology (ESC). Eur Heart J 2011; 32: 2999-3054.

3 Anderson JL, Adams CD, Antman EM, et al. 2012 ACCF/AHA focused update incorporated into the ACCF/AHA 2007 guidelines for the management of patients with unstable angina/non-ST-elevation myocardial infarction: a report of the American College of Cardiology Foundation/American Heart Association Task Force on Practice Guidelines. Circulation 2013; 127: e663-e828.

4 Chew DP, Aroney CN, Aylward PE, et al. 2011 Addendum to the National Heart Foundation of Australia/Cardiac Society of Australia and New Zealand Guidelines for the management of acute coronary syndromes (ACS) 2006. Heart Lung Circ 2011; 20: 487-502.

5 Aliprandi-Costa B, Ranasinghe I, Chow V, et al. Management and outcomes of patients with acute coronary syndromes in Australia and New Zealand, 2000-2007. Med J Aust 2011; 195: 116-121.

6 Antithrombotic Trialists' Collaboration. Collaborative meta-analysis of randomised trials of antiplatelet therapy for prevention of death, myocardial infarction, and stroke in high risk patients. BMJ 2002; 324: 71-86.

7 Lanas A, Wu P, Medin J, Mills EJ. Low doses of acetylsalicylic acid increase risk of gastrointestinal bleeding in a meta-analysis. Clin Gastroenterol Hepatol 2011; 9: 762-768.

8 Peters RJ, Mehta SR, Fox KA, et al; Clopidogrel in Unstable Angina to Prevent Recurrent Events (CURE) Trial Investigators. Effects of aspirin dose when used alone or in combination with clopidogrel in patients with acute coronary syndromes: observations from the Clopidogrel in Unstable angina to prevent Recurrent Events (CURE) study. Circulation 2003; 108: 1682-1687.

9 CURRENT-OASIS 7 Investigators, Mehta SR, Bassand JP, et al. Dose comparisons of clopidogrel and aspirin in acute coronary syndromes. NEngl J Med 2010; 363: 930-942.

10 Banoob DW, McCloskey WW, Webster W. Risk of gastric injury with enteric versus nonenteric-coated aspirin. Ann Pharmacother 2002; 36: 163-166.

11 Saini SD, Schoenfeld P, Fendrick AM, Scheiman J. Cost-effectiveness of proton pump inhibitor cotherapy in patients taking long-term, low-dose aspirin for secondary cardiovascular prevention. Arch Intern Med 2008; 168 : 1684-1690.

12 Yusuf S, Zhao F, Mehta SR, et al; Clopidogrel in Unstable Angina to Prevent Recurrent Events Trial Investigators. Effects of clopidogrel in addition to aspirin in patients with acute coronary syndromes without ST-segment elevation. NEngl J Med 2001; 345: 494-502. 
13 Byrne RA, Schulz S, Mehilli J, et al; Intracoronary Stenting and Antithrombotic Regimen: ISAR-SAFE Investigators. Rationale and design of a randomized, double-blind, placebo-controlled trial of 6 versus 12 months clopidogrel therapy after implantation of a drug-eluting stent: the Intracoronary Stenting and Antithrombotic Regimen: Safety And EFficacy of 6 Months Dual Antiplatelet Therapy After Drug-Eluting Stenting (ISARSAFE) study. Am Heart J 2009; 157: 620-624.e2.

14 Mauri L, Kereiakes DJ, Normand SL, et al. Rationale and design of the dual antiplatelet therapy study, a prospective, multicenter, randomized, double-blind trial to assess the effectiveness and safety of 12 versus 30 months of dual antiplatelet therapy in subjects undergoing percutaneous coronary intervention with either drug-eluting stent or bare metal stent placement for the treatment of coronary artery lesions. Am Heart J 2010; 160: 1035-1041.

15 Bhatt DL, Fox KA, Hacke W, et al. Clopidogrel and aspirin versus aspirin alone for the prevention of atherothrombotic events. N Engl J Med 2006; 354: 1706-1717.

16 Esposito G. Responsiveness to $\mathrm{P} 2 \mathrm{Y} 12$ receptor inhibitors. Curr Opin Cardiol 2011; 26 Suppl 1: S31-S37.

17 Bonello L, Tantry US, Marcucci R, et al. Consensus and future directions on the definition of high on-treatment platelet reactivity to adenosine diphosphate. J Am Coll Cardiol 2010; 56: 919-933.

18 Price MJ, Berger PB, Teirstein PS, et al; GRAVITAS Investigators. Standardvs high-dose clopidogrel based on platelet function testing after percutaneous coronary intervention: the GRAVITAS randomized trial. JAMA 2011; 305: 1097-1105.

19 Collet JP, Cuisset T, Rangé G, et al; ARCTIC Investigators. Bedside monitoring to adjust antiplatelet therapy for coronary stenting. NEngl J Med 2012; 367: 2100-2109.

20 Abraham NS, Hlatky MA, Antman EM, et al. ACCF/ACG/AHA 2010 Expert Consensus Document on the concomitant use of proton pump inhibitors and thienopyridines: a focused update of the ACCF/ACG/AHA 2008 expert consensus document on reducing the gastrointestinal risks of antiplatelet therapy and NSAID use: a report of the American College of Cardiology Foundation Task Force on Expert Consensus Documents. Circulation 2010 122: 2619-2633.

21 Bhatt DL, Cryer BL, Contant CF, et al. COGENT Investigators. Clopidogrel with or without omeprazole in coronary artery disease. N Engl J Med 2010; 363: 1909-1917.

22 Focks Jل, Brouwer MA, van Oijen MG, et al. Concomitant use of clopidogrel and proton pump inhibitors: impact on platelet function and clinical outcome - a systematic review. Heart 2013; 99: 520-527.

23 Wiviott SD, Braunwald E, McCabe CH, et al; TRITON-TIMI 38 Investigators. Prasugrel versus clopidogrel in patients with acute coronary syndromes. NEngl J Med 2007; 357: 2001-2015.

24 Roe MT, Armstrong PW, Fox KA, et al; TRILOGY ACS Investigators. Prasugrel versus clopidogrel for acute coronary syndromes without revascularization. NEngl J Med 2012; 367: 1297-1309.

25 Wallentin L, Becker RC, Budaj A, et al. Ticagrelor versus clopidogrel in patients with acute coronary syndromes. N Engl J Med 2009; 361: 1045-1057.

26 Task Force on the management of ST-segment elevation acute myocardial infarction of the European Society of Cardiology (ESC), Steg PG, James SK, et al. ESC Guidelines for the management of acute myocardial infarction in patients presenting with ST-segment elevation. Eur Heart J 2012; 33: 2569-2619.

27 Rothberg MB, Celestin C, Fiore LD, et al. Warfarin plus aspirin after myocardial infarction or the acute coronary syndrome: meta-analysis with estimates of risk and benefit. Ann Intern Med 2005; 143: 241-250.

28 Mega JL, Braunwald E, Wiviott SD, et al; ATLAS ACS 2-TIMI 51 Investigators. Rivaroxaban in patients with a recent acute coronary syndrome. NEngl J Med 2012; 366: 9-19.

29 Alexander JH, Lopes RD, James S, et al; APPRAISE-2 Investigators. Apixaban with antiplatelet therapy after acute coronary syndrome. N Engl J Med 2011; 365: 699-708

30 January CT, Wann LS, Alpert JS, et al. 2014 AHA/ACC/HRS Guideline for the management of patients with atrial fibrillation: a report of the American College of Cardiology/American Heart Association Task Force on Practice Guidelines and the Heart Rhythm Society. J Am Coll Cardiol 2014; Mar 26 [Epub ahead of print]. doi: 10.1016/j.jacc.2014.03.022.

31 Lamberts M, Gislason GH, Olesen JB, et al. Oral anticoagulation and antiplatelets in atrial fibrillation patients after myocardial infarction and coronary intervention. J Am Coll Cardiol 2013; 62: 981-989.

32 Dewilde WJ, Oirbans T, Verheugt FW, et al. Use of clopidogrel with or without aspirin in patients taking oral anticoagulant therapy and undergoing percutaneous coronary intervention: an open-label, randomised, controlled trial. Lancet 2013; 381: 1107-1115.

33 National Institute for Health and Clinical Excellence. Lipid modification: cardiovascular risk assessment and the modification of blood lipids for the primary and secondary prevention of cardiovascular disease. London: NICE, 2008. http://ww.nice.org.uk/CG67 (accessed Oct 2014).
34 Baigent C, Keech A, Kearney PM, et al. Efficacy and safety of cholesterollowering treatment: prospective meta-analysis of data from 90,056 participants in 14 randomised trials of statins. Lancet 2005; 366: 1267-1278.

35 Fonarow GC, Gawlinski A, Moughrabi S, Tillisch JH. Improved treatment of coronary heart disease by implementation of a Cardiac Hospitalization Atherosclerosis Management Program (CHAMP). Am J Cardiol 2001; 87: 819-822.

36 Briel M, Schwartz GG, Thompson PL, et al. Effects of early treatment with statins on short-term clinical outcomes in acute coronary syndromes: a meta-analysis of randomized controlled trials. JAMA 2006; 295: 2046-2056.

37 Cannon CP, Braunwald E, McCabe et al; Pravastatin or Atorvastatin Evaluation and Infection Therapy-Thrombolysis in Myocardial Infarction 22 Investigators. Intensive versus moderate lipid lowering with statins after acute coronary syndromes. NEngl J Med 2004; 350: 1495-1504.

38 Davidson MH, Robinson JG. Safety of aggressive lipid management. J Am Coll Cardiol 2007; 49: 1753-1762.

39 de Lemos JA, Blazing MA, Wiviott SD, et al. Early intensive vs a delayed conservative simvastatin strategy in patients with acute coronary syndromes: phase Z of the A to Z trial. JAMA 2004; 292: 1307-1316.

40 Grundy SM, Cleeman Jl, Merz CN, et al; Coordinating Committee of the National Cholesterol Education Program. Implications of recent clinical trials for the National Cholesterol Education Program Adult Treatment Panel III Guidelines. J Am Coll Cardiol 2004; 44: 720-732.

41 Finegold JA, Manisty CH, Goldacre B, et al. What proportion of symptomatic side effects in patients taking statins are genuinely caused by the drug? Systematic review of randomized placebo-controlled trials to aid individual patient choice. Eur J Prev Cardiol 2014; 21: 464-474.

42 Pandor A, Ara RM, Tumur I, et al. Ezetimibe monotherapy for cholesterol lowering in 2,722 people: systematic review and meta-analysis of randomized controlled trials. J Intern Med 2009; 265: 568-580.

43 Cannon CP, Giugliano RP, Blazing MA, et al; IMPROVE-IT Investigators. Rationale and design of IMPROVE-IT (IMProved Reduction of Outcomes: Vytorin Efficacy International Trial): comparison of ezetimbe/simvastatin versus simvastatin monotherapy on cardiovascular outcomes in patients with acute coronary syndromes. Am Heart J 2008; 156: 826-832.

44 Robinson JG, Nedergaard BS, Rogers WJ, et al; LAPLACE-2 Investigators. Effect of evolocumab or ezetimibe added to moderate- or high-intensity statin therapy on LDL-C lowering in patients with hypercholesterolemia: the LAPLACE-2 randomized clinical trial. JAMA 2014; 311: 1870-1882.

45 Stroes E, Colquhoun D, Sullivan D, et al; GAUSS-2 Investigators. Anti-PCSK9 antibody effectively lowers cholesterol in patients with statin intolerance: the GAUSS-2 randomized, placebo-controlled phase 3 clinical trial of evolocumab. J Am Coll Cardiol 2014; 63: 2541-2548.

46 Rubins HB, Robins SJ, Collins D, et al. Gemfibrozil for the secondary prevention of coronary heart disease in men with low levels of highdensity lipoprotein cholesterol. Veterans Affairs High-Density Lipoprotein Cholesterol Intervention Trial Study Group. N Engl J Med 1999; 341: 410-418.

47 Tenenbaum A, Motro M, Fisman EZ, et al. Bezafibrate for the secondary prevention of myocardial infarction in patients with metabolic syndrome. Arch Intern Med 2005; 165: 1154-1160.

48 Keech A, Simes RJ, Barter P, et al; FIELD study investigators. Effects of longterm fenofibrate therapy on cardiovascular events in 9795 people with type 2 diabetes mellitus (the FIELD study): randomised controlled trial. Lancet 2005; 366: 1849-1861.

49 Barter PJ, Caulfield M, Eriksson M, et al; ILLUMINATE Investigators. Effects of torcetrapib in patients at high risk for coronary events. N Engl J Med 2007 357: 2109-2122.

50 Schwartz GG, Olsson AG, Abt M, et al; dal-OUTCOMES Investigators. Effects of dalcetrapib in patients with a recent acute coronary syndrome. NEngl J Med 2012; 367: 2089-2099.

51 Cannon CP, Shah S, Dansky HM, et al; Determining the Efficacy and Tolerability Investigators. Safety of anacetrapib in patients with or at high risk for coronary heart disease. N Engl J Med 2010; 363: 2406-2415.

52 AIM-HIGH Investigators, Boden WE, Probstfield JL, et al. Niacin in patients with low HDL cholesterol levels receiving intensive statin therapy. NEngl J Med 2011; 365: 2255-2267.

53 HPS2-THRIVE Collaborative Group. HPS2-THRIVE randomized placebocontrolled trial in 25673 high-risk patients of ER niacin/laropiprant: trial design, pre-specified muscle and liver outcomes, and reasons for stopping study treatment. Eur Heart J 2013; 34: 1279-1291.

54 Schofield JD, France M, Ammori B, et al. High-density lipoprotein cholesterol raising: does it matter? Curr Opin Cardiol 2013; 28: 464-474.

55 Kromhout D, Yasuda S, Geleijnse JM, Shimokawa H. Fish oil and omega-3 fatty acids in cardiovascular disease: do they really work? Eur Heart J 2012; 33: 436-443.

56 Yusuf S, Peto R, Lewis J, et al. Beta blockade during and after myocardial infarction: an overview of the randomized trials. Prog Cardiovasc Dis 1985; 27: 335-371. 
57 Thygesen K, Alpert JS, Jaffe AS, et al; Joint ESC/ACCF/AHA/WHF Task Force for Universal Definition of Myocardial Infarction. Third universal definition of myocardial infarction. J Am Coll Cardiol 2012; 60: 1581-1598.

58 Tunstall-Pedoe H, Kuulasmaa K, Amouyel P, et al. Myocardial infarction and coronary deaths in the World Health Organization MONICA Project. Registration procedures, event rates, and case-fatality rates in 38 populations from 21 countries in four continents. Circulation 1994; 90 : 583-612.

59 A randomized trial of propranolol in patients with acute myocardial infarction. I. Mortality results. JAMA 1982; 247: 1707-1714.

60 Timolol-induced reduction in mortality and reinfarction in patients surviving acute myocardial infarction. N Engl J Med 1981; 304: 801-807.

61 Roberts R, Rogers WJ, Mueller HS, et al. Immediate versus deferred beta-blockade following thrombolytic therapy in patients with acute myocardial infarction. Results of the Thrombolysis in Myocardial Infarction (TIMI) II-B Study. Circulation 1991; 83: 422-437.

62 Thompson PL. Should $\beta$-blockers still be routine after myocardial infarction? Curr Opin Cardiol 2013; 28: 399-404.

63 Wiysonge CS, Bradley HA, Volmink J, et al. Beta-blockers for hypertension. Cochrane Database Syst Rev 2012; (11): CD002003. doi: 10.1002/14651858. CD002003.pub4.

64 Bangalore S, Steg G, Deedwania P, et al; REACH Registry Investigators. $\beta$-Blocker use and clinical outcomes in stable outpatients with and without coronary artery disease. JAMA 2012; 308: 1340-1349.

65 Chatterjee S, Biondi-Zoccai G, Abbate A, et al. Benefits of $\beta$ blockers in patients with heart failure and reduced ejection fraction: network metaanalysis. BMJ 2013; 346: f55.

66 Dargie HJ. Effect of carvedilol on outcome after myocardial infarction in patients with left-ventricular dysfunction: the CAPRICORN randomized trial. Lancet 2001; 357: 1385-1390.

67 Flather MD, Yusuf S, Køber L, et al. Long-term ACE-inhibitor therapy in patients with heart failure or left-ventricular dysfunction: a systematic overview of data from individual patients. ACE-Inhibitor Myocardial Infarction Collaborative Group. Lancet 2000; 355: 1575-1581.

68 Al-Mallah MH, Tleyjeh IM, Abdel-Latif AA, Weaver WD. Angiotensinconverting enzyme inhibitors in coronary artery disease and preserved left ventricular systolic function: a systematic review and meta-analysis of randomized controlled trials. J Am Coll Cardiol 2006; 47: 1576-1583.
69 Sorbets E, Labreuche J, Simon T, et al. Renin-angiotensin system antagonists and clinical outcomes in stable coronary artery disease without heart failure. Eur Heart J 2014; 35: 1760-1768.

70 Pfeffer MA, McMurray JJ, Velazquez EJ, et al. Valsartan, captopril, or both in myocardial infarction complicated by heart failure, left ventricular dysfunction, or both. NEngl J Med 2003; 349: 1893-1906.

71 Pitt B, Zannad F, Remme WJ, et al. The effect of spironolactone on morbidity and mortality in patients with severe heart failure. N Engl J Med 1999; 341: 709-717.

72 Pitt B, Remme W, Zannad F, et al. Eplerenone, a selective aldosterone blocker, in patients with left ventricular dysfunction after myocardial infarction. N Engl J Med 2003; 348: 1309-1321.

73 Juurlink DN, Mamdani MM, Lee DS, et al. Rates of hyperkalemia after publication of the Randomized Aldactone Evaluation Study. N Engl J Med 2004; 351: 543-551.

74 Effect of verapamil on mortality and major events after acute myocardial infarction (the Danish Verapamil Infarction Trial II-DAVIT II). Am J Cardiol 1990; 66: 779-785.

75 Multicenter Diltiazem Post-infarction Trial Research Group. The effect of diltiazem on mortality and reinfarction after myocardial infarction. The Multicenter Diltiazem Postinfarction Trial Research Group. NEngl J Med 1988; 319: 385-392.

76 Packer M, O'Connor CM, Ghali JK, et al. Effect of amlodipine on morbidity and mortality in severe chronic heart failure. N Engl J Med 1996; 335: 1107-1114.

77 Teo KK, Yusuf S, Fuberg CD. Effects of prophylactic antiarrhythmic drug therapy in acute myocardial infarction. An overview of results from randomized controlled trials. JAMA 1993; 270: 1589-1595.

78 ISIS-4: a randomised factorial trial assessing early oral captopril, oral mononitrate, and intravenous magnesium sulphate in 58,050 patients with suspected acute myocardial infarction. ISIS-4 (Fourth International Study of Infarct Survival) Collaborative Group. Lancet 1995; 345: 669-685.

79 Faris R, Flather M, Purcell H, et al. Current evidence supporting the role of diuretics in heart failure: a meta analysis of randomised controlled trials. Int J Cardiol 2002; 82: 149-158.

80 Digitalis Investigation Group. The effect of digoxin on mortality and morbidity in patients with heart failure. N Engl J Med 1997; 336: 525-533. $\square$ 